\title{
Digital billboards dynamic luminance measurements
}

\author{
Piotr Tomczuk ${ }^{1, *}$, and Anna Wytrykowska ${ }^{1}$ \\ ${ }^{1}$ Warsaw University of Technology, Faculty of Transport, 75 Koszykowa Street, 00-662 Warsaw, \\ Poland
}

\begin{abstract}
In the opinion of the drivers, digital billboards and telebims are a potential threat to road traffic. Multimedia content with dynamically changing luminance level over time is often presented on emission media. The problem was highlighted when trying to regulate the requirements for dynamic media in law. The Ministry of Infrastructure and Development is in the process of drafting regulations aimed at limiting the emission parameters of light commercials used in the road environment. The limitation is to apply to the maximum luminance parameters emitted during the daylight and night, with the limitation to the built-up area and outside the built-up area. It is also proposed to limit the switching time of the image sequence and its luminance level. In the article have been describe the test procedure with presented sample measurement results. The object of research was medium-size advertising, where the illuminating surface was made with the use of semiconductor LED light sources. Obtained results undoubtedly indicate that there is a problem with measuring the parameters of advertising luminance with dynamically changing content.
\end{abstract}

\section{Introduction}

From among all the carriers of visual information placed by advertisers of the roads environments, electronic advertisements displaying dynamically changing content are potentially dangerous. These are usually solutions where the carrier is a source of coloured light emitted by means of light-emitting diodes [1,2]. Electronic advertisements, contrary to traditional advertisements (e.g. static billboards), are characterized by high brightness and the possibility of dynamic change of displayed images $[1,3,4]$. This is particularly important at night, when the bright surfaces of electronic advertising in the drivers' field of vision can cause discomfort in observing the road, other road users, obstacles and thus make it difficult for the driver to perform the visual tasks associated with driving. As indicated in publication [5], drivers at night pay more attention to electronic advertising than to other signs and static advertising. According to the survey results presented in the study [5], electronic media attract drivers' attention for a longer period of time.

Both in Poland [1-4,6,7] and worldwide [8-11] research works were carried out indicating the problem of the influence of light from electronic media on drivers' behaviour.

\footnotetext{
* Corresponding author: ptomczuk@wt.pw.edu.pl
} 
The publications shall highlight the impact of electronic advertising on drivers' attention, particularly at night. As shown in the report of 2006 [12], dynamic images (films) or flickering of the image visible by the driver distract the driver's attention to a degree higher than static images. The presence of dynamic variable content media in an environment of junctions or roads with complex road layout can lead to driver distraction. The results of research conducted in 2012 [10], in road conditions with the use of eye-tracking tools, confirmed that the vast majority of drivers look more often and longer at electronic advertisements than at road signs. It was also found that advertisements, whose images change more frequently than every 7 seconds, attract the attention of drivers rather than road signs. However, it is not always observed that advertising media have a significant statistical impact on the incidence of accidents in the area of their occurrence [13]. Despite the lack of recorded traffic events, there may be a negative impact of the media on drivers' behaviour $[8,9,14]$ e.g. the following: - short-term loss of the ability to control the situation in front of the vehicle caused by eye fixation on the carrier, occurrence of driver glare causing temporary sight dysfunction and re-adaptation to the conditions of night observation of the road and its surroundings, misinterpretation of traffic lights due to the similar color and shape of the traffic light.

In many countries, attempts have been made to reduce the negative impact of electronic advertising on driver distraction [15-19] So far, there have been no uniform international requirements for this type of advertising. In a number of countries there are local recommendations [6,7] [20] or regulations, e.g. Australia [21], Abu Dhabi [15], UK [22,23], Sweden, Netherlands, South Africa, selected US states [14,23]. With regard to the influence of light from electronic media, existing regulations indicate the need to limit the possibility of displaying moving images, to limit the minimum time of displaying an advertisement, to limit the visual effects and the intervals between the images displayed sequentially. limit the maximum luminance of the advertising medium.

Also in Poland, provisions have been introduced to limit the emission of dynamic light from advertising media [24]. According to the draft implementing legislation, light advertising near a road in a built-up area will not be allowed to emit more than $4000\left(\mathrm{~cd} / \mathrm{m}^{2}\right)$ of light per day and $600\left(\mathrm{~cd} / \mathrm{m}^{2}\right)$ per night. Outside the built-up area, the advertisement may not have a lighting area of more than $4000\left(\mathrm{~cd} / \mathrm{m}^{2}\right)$ per day and $400\left(\mathrm{~cd} / \mathrm{m}^{2}\right)$ per night. The values proposed in the draft regulation represent a significant reduction in the clarity of advertising. The technical parameters of modern RGB LED matrices used in the construction of advertising media screens allow to obtain high luminance of the emission surface (often above $10000 \mathrm{~cd} / \mathrm{m}^{2}$ ). According to the draft regulation, the luminance of an advertisement will not be changed more quickly than $200\left(\mathrm{~cd} / \mathrm{m}^{2}\right)$ per second, which means that advertisements will not be able to change luminance levels quickly, thus distracting the driver from observing the road scene.

\section{Procedure for the measurement of variable advertising luminance}

The introduction of legal regulations [24] limiting the possibility of emission and displaying excessive luminance levels makes it necessary to control the assumed emission levels and the time of displaying information on the medium. 


\subsection{Weather conditions during luminance measurement}

The first step of the procedure is to determine whether it is possible to carry out measurements. In the case of luminance measurements, the test surface must be dry $[1,2]$, with no precipitation, haze, dew, etc. The temperature at which the measurement is carried out shall be within the limits permitted by the manufacturer of the measuring instrument used. Any deviation from the rules presented has the effect of distorting the luminance measurement results, as it is a value strongly dependent on the condition of the tested surface (changes in the surface emission coefficients or the nature of the light reflection).

\subsection{Geometric dimensions of the advertising}

The next step in the procedure is to determine the geometric dimensions of the advertising media. Taking into account the angular size of the measuring field of the available measuring instrument, the permissible measuring distance [1,2] has to be determined. In the case of dynamic luminance measurements, the measuring field of the luminance meter shall be within the geometric dimensions of the advertising media several times. The basic geometrical parameters should be defined, i.e.: width of the medium (m), height of the medium (m), surface area of the medium (calculated parameter) $\left(\mathrm{m}^{2}\right)$. If it is necessary, it is possible to define other geometrical features, which are variable in each situation and depend on the specific installation of the medium, i.e: height of installation of the advertising medium (to the middle) $(\mathrm{m})$, angle of installation of the medium in relation to the road $\left(^{\circ}\right)$, distance of installation of the medium from the road edge (the side of the medium) (m), measurement distance (the medium - the meter) $(\mathrm{m})$, determination of the location side in relation to the road (parameter unchanged: right, left), angular size of the object (calculated) $\left(^{\circ}\right)$.

\subsection{Record advertising luminance changes}

The main purpose of the measurement is to find the maximum luminance value (when displaying the sequence of images), which is the parameter determining the possibility of the media to be put into service. According to the literature $[1,2,6,7]$ the highest luminance value is obtained for measurements taken from the direction perpendicular to the carrier. However, due to possible directions of observation of drivers [3,4], the measuring head should be directed at the advertisement from the height taking into account the position of the driver's eyes in the vehicle [1,2], i.e. 1,5 meter.

In the case of dynamic measurements of advertising media with variable content, the meter used should allow for measurement and continuous recording of the luminance value of the illuminating surface. When measured with the classic luminance meter [1-4], which is not suitable for quick variable signal measurement, it is not possible to record transient states of the displayed content (i.e. changes in luminance levels over time) [1,2]. It is therefore necessary to measure luminance at a high sampling rate (minimum $10 \mathrm{~Hz}$ ) and with a small measuring field (maximum $1^{\circ}$ ). Analyses $[1,2]$ show that the angular size of the $1^{\circ}$ measurement field is sufficient to measure most of the existing advertising media. The angular size of the measuring field should not be too large to accurately measure the luminance of the advertising surface at a sufficiently large number of measurement points, and at the same time should not cause excessive averaging of the luminance values in the surveyed area [1,2]. When examining a dynamically variable advertisement, the entire sequence of displayed content on the media and the corresponding luminance levels shall be recorded. 


\subsection{Example of luminance and exposure time measurement of dynamic advertising media content}

The luminance of dynamic advertising was measured with a prototype GL Photometer equipped with dedicated GL LumiMeter LM 1.0 software. The measuring device (Fig.1 a) was perpendicular to the tested medium (Fig. $1 \mathrm{~b}, 2)$ at a distance of $r=10 \mathrm{~m}$. The measuring field of the meter was inside the measured plane defined by two dimensions: HFOV (Horizontal Field of View), horizontal viewing angle, and VFOV (Vertical FOV) - vertical viewing angle. Fig. $1 \mathrm{c}$ ) shows the tested advertising medium with dimensions of $2.5 \mathrm{~m} \mathrm{x} 0.8$ $\mathrm{m}$ and dynamically variable content (cyclic change of luminance level) for which the luminance level was recorded.

a)

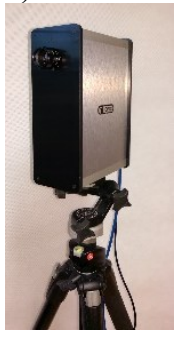

b)

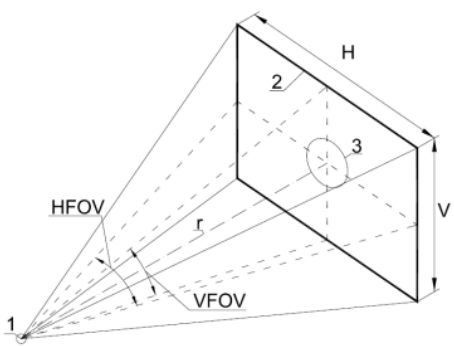

c)

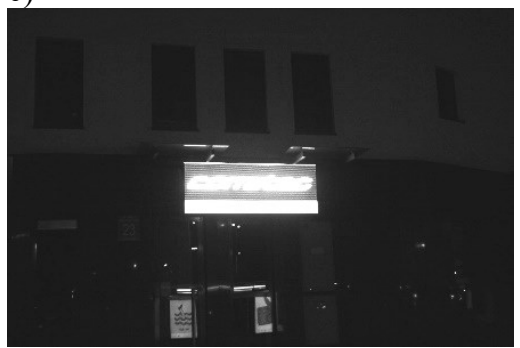

Fig. 1. GLPhotometer Dynamic luminance meter, location of the meter in relation to the dynamic medium and the measured object.

Figure 2 shows the changes in the luminance level of the emission area. The displayed content is indicated by digits. The beginning and end of the sequence are marked.

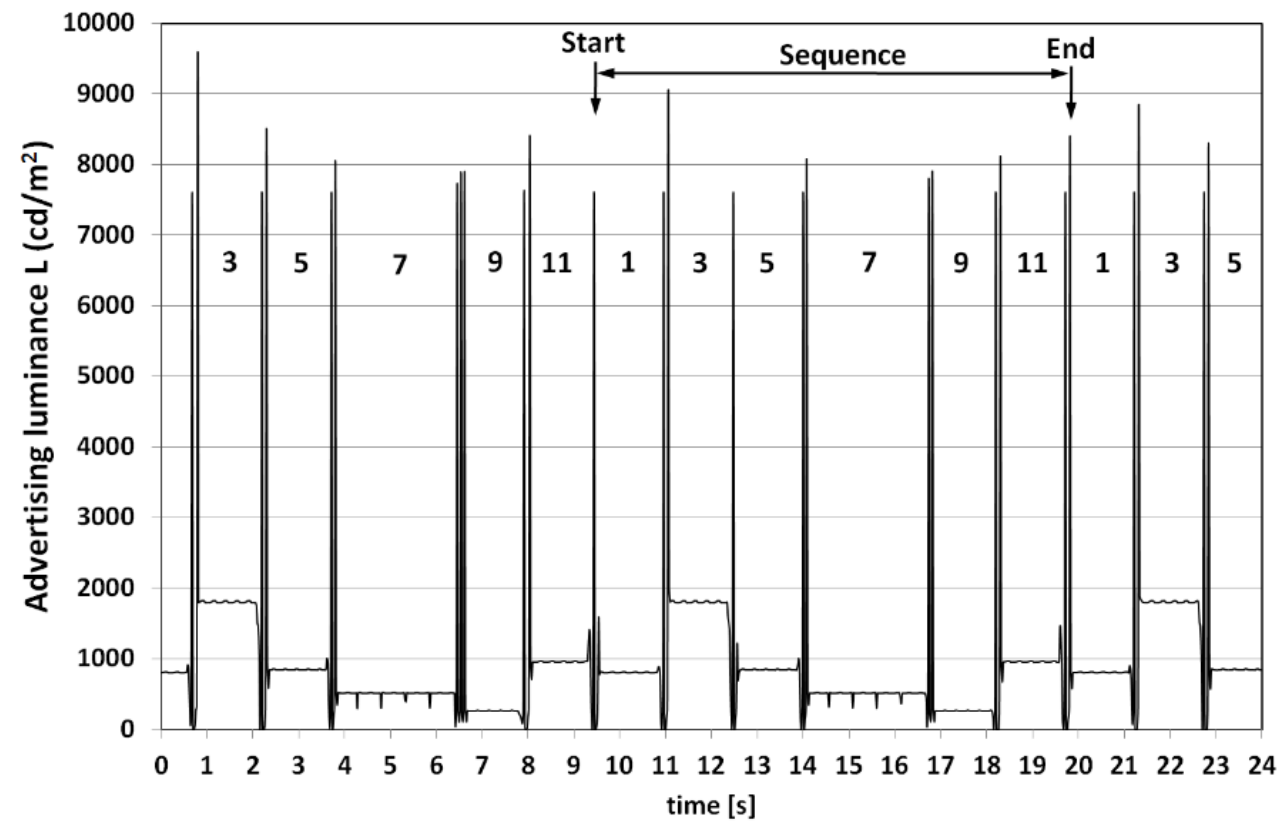

Fig. 2. Recorded changes in the luminance of the surface of an advertisement media due to a change in the sequence of displayed images.

Table 1 summarizes one sequence of displayed images, together with the duration of a single image and the corresponding maximum luminance. 
Table 1. Sequence of change of parameter for luminance of electronic advertisement.

\begin{tabular}{|c|c|c|c|c|}
\hline 1.p. & Photo & $\begin{array}{c}\text { Time sequence } \\
\text { (s) }\end{array}$ & Period (ms) & $L_{\max }\left(c d / m^{2}\right)$ \\
\hline 1 & $=-\operatorname{ser}=\Rightarrow$ & $9,56 \div 10,86$ & 1300 & 885,2 \\
\hline 2 & & $10,86 \div 11,06$ & 200 & 9052,0 \\
\hline 3 & & $11,06 \div 12,44$ & 1380 & 1985,0 \\
\hline 4 & & $12,44 \div 12,56$ & 120 & 7607,0 \\
\hline 5 & & $12,56 \div 13,96$ & 1400 & 860,1 \\
\hline 6 & & $13,96 \div 14,10$ & 140 & 8084,0 \\
\hline 7 & & $14,1 \div 16,70$ & 2600 & 521,2 \\
\hline 8 & & $16,70 \div 16,86$ & 160 & 7902,0 \\
\hline 9 & & $16,86 \div 18,14$ & 1280 & 283,9 \\
\hline 10 & & $18,14 \div 18,34$ & 200 & 8120,0 \\
\hline 11 & Fit & $18,34 \div 19,60$ & 1260 & 969,9 \\
\hline 12 & & $19,60 \div 19,84$ & 240 & 8402,0 \\
\hline
\end{tabular}


From the presented results of measurements of dynamic media (Fig. 2 and Table 1) it can be concluded that the luminance values significantly exceed the limits planned for the introduction of Polish legal regulations [24]. The advertising medium for images no. 1,3,5,11 (Table 1) produced luminance values exceeding $600\left(\mathrm{~cd} / \mathrm{m}^{2}\right)$. According to the recommendations, the luminance levels were obtained only for images no. 7 and 9. On the other hand, all the displayed odd-numbered sequences were connected with a white image (with a very high luminance, photo no. 2, 4, 6, 8, 10 and 12) close to or exceeding 8000 $\left(\mathrm{cd} / \mathrm{m}^{2}\right)$. The generation of short-term light flashes affects the attention of drivers and is not permitted in the light of the new regulations [24].

\section{Summary}

The maximum luminance values proposed in ordinance [24] will limit the possibility of emission and displaying excessive luminance levels from dynamic media located in the road environment. The regulations will be effective only if procedures and measurement tools are introduced to verify of the level and time of light emission from the advertising medium. The currently available measuring instruments (luminance meters) allow to verification of the parameters proposed in ordinance [24] only to a limited extent. The aim is to harmonise the measurement procedure and to use tools that enable the luminance level of a dynamic medium to be verified unequivocally.

Issues presented in this article are the subject of research and analysis in a project carried out by the Faculty of Transport of the Warsaw University of Technology entitled: The impact of advertisements on the level of road traffic safety, contract number: DZP/RID-I-33/4/NCBR/2016 (Registration of Road Innovation), financed by the National Centre for Research and Development and the General Directorate for National Roads and Motorways.

\section{References}

1. M. Chrzanowicz, P. Tomczuk, P. Jaskowski, Methodology of Measuring the luminance surface advertisting media which emits lights, Pr. Nauk. Politech. Warsz. Transp. 118 (2017) 49-60.

2. M. Chrzanowicz, P. Tomczuk, Research on the parameters of light emitting advertising media, MATEC Web Conf. 122 (2017) 03002. doi:10.1051/matecconf/201712203002.

3. K. Wandachowicz, M. Zalesińska, K. Domke, S. Mroczkowska, P. Skrzypczak, Wielkopowierzchniowe reklamy $\mathrm{z}$ diodami świecącymi a bezpieczeństwo ruchu drogowego, Przegląd Elektrotechniczny. $87 \quad$ (2011) 73-77. http://yadda.icm.edu.pl/baztech/element/bwmeta1.element.baztech-article-BPS10044-0058 (accessed July 1, 2017).

4. M. Zalesińska, K. Wandachowicz, The research of outdoor billbords with light emitting diode using luminance measuring camera, Pozn. Univ. Technol. Acad. Journals. Electr. Eng. 69 (2012) 275-282.

5. S.E. Lee, M.J. Mcelheny, R. Gibbons, Driving Performance and Digital Billboards, Prepared for: Foundation for Outdoor Advertising Research and Education, 2007. http://omac-website.s3.amazonaws.com/wp-content/uploads/2016/03/DrivingPerformance-Digital-Billboards-VTTI-Study.pdf (accessed July 1, 2017).

6. K. Domke, K. Wandachowicz, M. Zalesińska, S. Mroczkowska, P. Skrzypczak, Ocena zagrożeń występujących $w$ ruchu drogowym powodowana przez wielkopowierzchniowe reklamy z diodami świecącymi, work no. 42-17-223-42050, grant no. RoM. III/3420-50/10, Poznan, 2010. 
7. K. Domke, M. Zalesińska, Wielkoformatowe elektroniczne reklamy a bezpieczeństwo użytkowników ruchu drogowego, Logistyka. 3 (2014) 1351-1361.

8. D. Beijer, Driver distraction due to roadside advertising, University of Toronto, Department of Mechanical and Industrial Engineering., 2002.

9. D. Beijer, A. Smiley, M. Eizenman, Observed Driver Glance Behavior at Roadside Advertising Signs, Transp. Res. Rec. J. Transp. Res. Board. 1899 (2004) 96-103. doi:10.3141/1899-13.

10. T. Dukic, C. Ahlstrom, C. Patten, C. Kettwich, K. Kircher, Effects of Electronic Billboards on Driver Distraction, Traffic Inj. Prev. 14(5) (2013) 469-476. doi:10.1080/15389588.2012.731546.

11. Effects of roadside advertisements on road safety, Finnra Internal Reports 25/2004, Helsinki, 2004. http://alk.tiehallinto.fi/julkaisut/pdf/4000423e-veffectsofroadside.pdf (accessed June 22, 2017).

12. S. Speirs, A. Winmill, T. Kazi, The Impact of Roadside Advertising on Driver Distraction: Final Report, WSP Development and Transportation, Basingstoke, 2008.

13. D. Shinar, Traffic safety and human behavior, Emerald Group Publishing Limited, 2007.

https://books.google.pl/books/about/Traffic_Safety_and_Human_Behavior.html?id=D q-dhkuGVZEC\&redir_esc=y (accessed October 16, 2018).

14. P.R. Boyce, Lighting for driving: roads, vehicles, signs, and signals, Taylor \& Francis Group, USA, 2009.

15. Deparment of Transport United Arab Emirates, Roadside advertising manual, Document No: AD-R-03 First Edition, Abu Dhabi, 2013.

16. Guideline: Roadside Advertising Guide, Edition 1.2, Departament of Transport and Main Roads, Australia, 2013.

17. Illuminating Engineering Society of North America, TM-11-00, Light Trespass: Research, Results, and Recommendations, New York, USA, 2000.

18. T. Mackun, K. Jamroz, J. Żukowska, J. Rychlewska, Zagrożenia dla uczestników ruchu drogowego stwarzane przez reklamy widziane z drogi, Drogownictwo. 4-5 (2015) 134141.

19. Road Safety Committee, Inquiry into Driver Distraction, Victoria, Australia, 2006. https://www.parliament.vic.gov.au/images/stories/committees/rsc/driver_distraction/D istraction_Final_Report1.pdf (accessed October 18, 2018).

20. J. Żukowska, Comparison of requirements for location, maintenance and removal of road advertising between polish and foreign regulations, MATEC Web Conf. 122 (2017) 03013. doi:10.1051/matecconf/201712203013.

21. Government Queensland Department of Main Roads, TERS Guide to the Management of Roadside Advertising, 1.0, 2002.

22. The Institution of Lighting Professionals, PLG05 The Brightness of Illuminated Advertisements, Institution of Lighting Professionals, 2015.

23. S. Speirs, A. Winmill, T. Kazi, The Impact of Roadside Advertising on Driver Distraction: Final Report. Basingstoke, Hampshire, England: WSP Development and Transportation, 2008.

24. Act of 24 April 2015 amending certain acts on strengthening the tools for landscape protection, OJ 2015 Pos. 774, Poland, 2015.

25. I. Lewin, Digital Billboard Recommendations and Comparisons to Conventional Billboards, Lighting Sciences Inc., Arizona, 2008. 